of dental caries it follows that there is every likelihood that it continues into the permanent dentition and adulthood.

M. E. J. Curzon

Northallerton, North Yorkshire

DOI: 10.1038/sj.bdj.2015.300

\section{ORAL CANCER}

\section{Two cancer cases in a career?}

Sir, it used to be an anecdote that a dentist might only see two cases of oral cancer in their entire career. But was, or is, that true? Recalculation may be needed because, although there are many more dentists $(40,000)$, the incidence of oral cancer has risen sharply (three-fold) in the last 30 years without a marked increase in population size. Factoring in potentially malignant, possibly pre-cancerous lesions, we will all be seeing clinically significant cases each year.

Approximately $60 \%$ of the population attend the dentist regularly (38.4 million people). ${ }^{1}$ If we reflect this attendance pattern in the 6,767 cases of mouth cancer per year, then 4,060 patients would have attended their dentist; approximately one oral cancer per ten dentists or conversely, one case per 9,500 patients seen. If we then add in potentially malignant lesions (erythroplakia, leukoplakia, submucous fibrosis, lichenoid lesions) at a population rate of $2.5 \%,{ }^{2,3}$ then we might expect to see 24 premalignant lesions per year (960,000 amongst 40,000 dentists), which is two a month.

Where cancer is suspected, the patient should be urgently referred to be seen within two weeks. ${ }^{4}$ Furthermore, with an increase in oropharyngeal lesions that may spread to cervical lymph nodes, dentists should carefully check for swellings in the neck every time a patient attends, as well as a careful clinical examination of the entire oral mucosa. This may be particularly important in irregular attenders, as that may be the one chance for early detection, which could quite literally save that person's life.

G. R. Ogden, Dundee C. Scully, S. Warnakulasuriya, London P. Speight, Sheffield

1. Health and Social Care Information. Adult Dental Health Survey 2009 - Summary report and thematic series [NS]. 2011, Available online at: http:// www.hscic.gov.uk/pubs/dentalsurveyfullreport09 (accessed April 2015).

2. Lim K, Moles D R, Speight P M. Opportunistic screening for oral cancer and precancer in general dental practice: results of a demonstration study. Br Dent J 2003; 194: 497-502.

3. Warnakulasuriya S, Kovacevic T, Madden P et al. Factors predicting malignant transformation in oral potentially malignant disorders among patients accrued over a 10 -year period in South East England. J Oral Pathol Med 2011; 40: 677-683. 4. National Institute for Health and Care Excellence (NICE). Referral guidelines for suspected cancer. 2005. Available online at: https://www.nice.org.uk/ guidance/cg27/chapter/referral-timelines (accessed April 2015).

DOI: $10.1038 /$ sj.bdj.2015.302

\section{DENTAL REGULATION}

\section{In conflict with the GMC}

Sir, in fear of being accused of 'hitting a man when he is down', I do believe the General Dental Council (GDC) needs to clarify its position with respect to patient confidentiality. The regulation/advice of the GDC appears to be in conflict with that of the General Medical Council (GMC) on this matter. ${ }^{1,2}$

The GMC's advice to its registrants clearly states that any information given to a medical practitioner is assumed eligible to be disclosed to other healthcare professionals involved in the patient's care unless the patient declares otherwise. The GDC's advice appears to read that the patient must give their stated permission for this information to be disclosed. It would appear the only secure way that a GDC registrant can claim they have that permission is to have written consent for that disclosure from the patient.

Clearly, any practitioner in secondary care replying to a healthcare professional who has referred the patient to them could be challenged on the information given in their reply unless the patient gives their specific authority to disclose any information. Surely, the GDC should reconsider its advice, and do as the GMC have advised, and clearly state that implied consent for information disclosure to other healthcare professionals is assumed unless otherwise stated by the patient. Should my interpretation of the regulation be correct where does it place those colleagues who hold both GDC and GMC registration? A ridiculous situation could arise where a joint GMC and GDC registrant satisfies one of their regulatory authorities and not the other. How can such a situation be both fair to a patient and the registrant?

\section{G. D. Wood} Wirral

1. General Dental Council. Standards for the Dental Team. Paragraph 4.25. London: GDC, 2013.

2. General Medical Council. Confidentiality guidance: Disclosing information with consent. Paragraphs 24-26. Manchester: GMC, 2009.

DOI: 10.1038/sj.bdj.2015.303

\section{The overriding objective}

Sir, readers may be interested in my recent experience in front of the GDC's Registration Appeals Committee for a deficiency of 48 hours of non-verifiable continuing professional development (CPD) which would seem to contradict Council's professed policy of proportionality.

There is no legal compulsion for any of the health regulatory bodies to act proportionally. However, for the GDC to publicise at every possible occasion their policy of proportionality leading dentists to expect them to act proportionally is a commitment, which if not met, is flawed and unlawful. Only two months ago the Council's Chairman wrote a 'Dear Registrant' letter which finished - 'We all have a common objective, a high quality 
service working with a proportionate regulatory system.' In front of the Health Select Committee the Registrar continually referred to the word 'proportional'.

There is a principle in the Civil Procedure Rules referred to as the 'overriding objective'. The principle also applies to those professions under the Professional Regulatory Authority. The overriding objective includes the proviso that cases should be dealt with in ways that are proportional to the nature, importance and complexity of the issues. Is a notice of erasure and subsequent oral appeal for a shortfall of 48 hours of non-verifiable CPD important? Is it complex? Does it warrant the Council's threat to instruct solicitors and counsel with a possible costs order of $£ 6,000$ in the event that the appeal fails?

The proportionality issue was enhanced by the fact that only six days before my appeal a policy paper 'Enhanced continuing professional development scheme' was put out for consultation. This in effect recognised the short comings of nonverifiable $\mathrm{CPD}$ as a box ticking exercise with little recognition of learning outcomes. The Council never referred to this policy document and the Committee were unaware of its existence.

The determination not to erase my name from the Dentists Register gives me little pleasure. Apart from registrants having to fund the all-day hearing, there are probably many cases in the pipeline that are completely out of proportion to the alleged wrongdoing.

\section{E. Gordon}

Finchley

DOI: $10.1038 /$ sj.bdj.2015.304

Editor's note: further information about this particular case can be found in the news section of this issue.

\section{DENTAL PUBLIC HEALTH}

\section{Community action}

Sir, thank you for your editorial advocating water fluoridation as a safe and efficacious measure to assuage the physical, economic, social, psychological and emotional repercussions of dental caries. ${ }^{1}$ Regrettably, dental caries remains a major public health concern in high and low income countries; wreaking havoc on entire communities, bringing in its wake anguish, torment, starvation, weight loss, growth retardation, health and social inequities and even death. The mouth is the gateway to our bodies and intuitively, oral and systemic diseases share common risk factors/pathogenic pathways. ${ }^{2}$ It has long

\section{THE POWER OF DATA}

Sir, we are waiting impatiently for the outcome of the review of the current situation in the UK regarding antimicrobial prophylaxis against infective endocarditis (IE) and the 2008 NICE guidelines (GC64) as announced by NICE in November 2014.

The research work that has finally motivated this immediate re-evaluation has been recently published in The Lancet by a group of British and American professors in cardiology, oral medicine and infectious diseases. ${ }^{1}$ They conclude that prescriptions of antibiotic prophylaxis have fallen substantially and the incidence of IE has increased significantly in England since the introduction of the 2008 NICE guidelines. This is not just a key moment for all our dental colleagues but also a hugely inspirational event, which, once again, highlights the importance and the power of data. It reinforces the need for data collection and, I imagine, pays off all the hard work invested in a national research project of that scale.

I cannot further emphasise enough that all dental professionals should be competent on recognising the signs and

being argued that oral and systemic health are determined by a multitude of common risk factors from dietary intake, smoking, alcohol consumption and poor oral hygiene to commensal microbial communities colonising our mucous membranes, destabilising our oral ecosystems and causing diseases

The global nature of health in contemporary times is complex, as was demonstrated recently during the Ebola virus outbreak in West Africa; human health is inexorably intertwined with a rich and diverse tapestry of political, economic, social, animal, cultural, ethical, religious, behavioural, digital and environmental underpinnings. ${ }^{3}$ The situation is further complicated by the budding of public, private and non-governmental factors with absolute shrinking in the sovereignty and realm of governments. Oral health cannot be seen in isolation. Therefore, health strategists can enhance oral and general health by encouraging community involvement, group spirit and partnerships, and emphasising the relationship between oral and general health within a prosperous society.

M. F. Al Qutob London symptoms of IE, remain informed about such a potentially fatal pathological entity and be aware of how its diagnosis is reached and what its initial management involves. This valuable knowledge will allow us to explain the rationale behind the current guidelines and probable future changes, better educating our patients and most importantly promoting preventive dentistry and medicine to reduce the overall risk.

Perhaps, as Bach has very rationally suggested, until more definitive trials are performed, involving patients in an informed decision-making process and individualisation of cases, in liaison with our cardiology colleagues, when antibiotic prophylaxis is considered, there seems to be a more ethical approach. ${ }^{2}$

\section{A. De Gea Rico, L. R. Williams,}

London

1. Dayer $\mathrm{M} \mathrm{J}$, Jones $\mathrm{S}$, Prendergast $\mathrm{B}$, Baddour $\mathrm{L} \mathrm{M}$, Lockhart P B, Thornhill M H. Incidence of infective endocarditis in England, 2000-13: a secular trend, interrupted time-series analysis. Lancet 2014; DOI: 10.1016/S0140-6736(14)62007-9.

2. Bach D S. Antibiotic prophylaxis for infective endocarditis: ethical care in the era of revised guidelines. Methodist Debakey Cardiovasc J 2010; 6: 48-52.

DOI: 10.1038/sj.bdj.2015.307
1. Hancocks S. Editorial: Will someone explain please? Br Dent J 2015; 218: 263.

2. Sheiham A, Watt R. The common risk factor approach: a rational basis for promoting oral health. Community Dent Oral Epidemiol 2000; 28: 399-406.

3. Bhopal A. Attitude and the 21st century doctor. Lancet Glob Health 2015; 3: e126-e127.

DOI: 10.1038/sj.bdj.2015.305

\section{EQUIPMENT QUALITY}

\section{Counterfeit cables}

Sir, I write in relation to your recent editorial The artfulness of the fake (BDJ 2015; 215: 317). I would like to inform of an experience which I had recently.

I purchased an iPad mini as a Christmas gift for my disabled sisterin-law in 2013 from Apple store. I received a beautifully packaged product with which she was delighted. Unfortunately, two months later it would not charge because the device decided that the charging cable was a counterfeit (supplied by Apple).

My sister-in-law's Lithuanian carer gave her a cable which she had purchased in the local market for $\$ 2$ which is working perfectly! Makes one wonder.

J. Gilleece By email DOI: 10.1038/sj.bdj.2015.306 